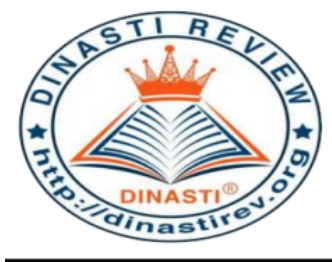

+62 878-9658-6407

087896586407

https://dinastirev.org/JIMT

editor@dinastirev.org

\title{
ANALISIS STRATEGI PENGEMBANGAN USAHA PERJALANAN WISATA PADA PT. HASRAT LESTARI GEMILANG
}

\section{Rosana Mia Agusty ${ }^{1)}$}

${ }^{1)}$ Universitas Mercu Buana, Jakarta, Indonesia

ARTICLE INFORMATION

Received: 13 April 2020

Revised: 25 April 2020

Issued: 2 Mei 2020

Corresponding Author:

Rosana Mia Agusty

E-mail:

55119110030@student.mercubuana.ac.id

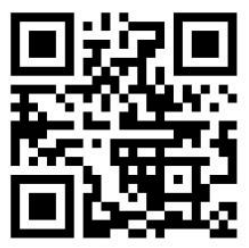

DOI:10.31933/JIMT
Abstrak: PT. Hasrat Lestari Gemilang (PT. HLG) adalah perusahaan yang bergerak di bisnis perjalanan wisata dalam negeri maupun luar negeri, berdiri di tahun 2018. Permasalahan yang dihadapi adalah belum memiliki strategi bisnis yang telah melalui proses analisis. Tujuan penelitian ini untuk melakukan analisis lingkungan internal eksternal serta memberikan rekomendasi untuk menerapkan strategi yang tepat. Penelitian ini juga ditujukan untuk membantu perusahaan mencapai visi dan misi yang diharapkan tercapai pada tahun 2025. Metode yang digunakan adalah metode deskriptif kuantitatif. Teknik pengumpulan data dengan melakukan wawancara seluruh karyawan PT. HLG untuk memperoleh gambaran lengkap mengenai kondisi internal eksternal yang mempengaruhi perkembangan perusahaan. Data yang diperoleh dianalisis dengan pendekatan Resource-Based View dan metode scanning, monitoring, forecasting, dan assessing, serta matriks SWOT. Hasil analisis SWOT adalah 2.47 untuk penilaian analisis lingkungan internal dan 3.50 untuk penilaian analisis lingkungan eksternal. Strategi bisnis yang sesuai adalah penetrasi pasar, pengembangan produk, pengembangan pasar, dan integrasi horisontal.

Kata kunci: analisis SWOT, penetrasi pasar, pengembangan produk, pengembangan pasar, integrasi horisontal

\section{PENDAHULUAN}

BPS (Badan Pusat Statistik) melaksanakan sensus penduduk pada tahun 2020 dan diharapkan dapat selesai dan digunakan sebagai panduan pembangunan oleh pemerintah daerah pada akhir Desember 2020. Data jumlah penduduk Indonesia pada tahun 2019 adalah sebesar 269.536.482 orang, yang membuat Indonesia berada pada urutan ke 4 dengan penduduk tertinggi setelah Cina, India, dan Amerika Serikat. Indonesia adalah negara kepulauan dengan beragam suku budaya, Bahasa, tradisi, dan landscape. Setiap wilayah di Indonesia memiliki ciri khas tersendiri baik dari Bahasa, bentuk bangunan, baju adat, serta keindahan alam yang merupakan daya tarik wisata bagi masyarakat Indonesia maupun wisatawan asing. 
Dalam kesempatan membuka Astindo Travel Fair 2019 di Jakarta Convention Center, Jumat, 22 Februari 2019, Ketua Umum Asosiasi Indonesia (Astindo) Elly Hutabarat mengatakan, tren traveling masyarakat Indonesia saat ini meningkat signifikan. Hal tersebut terlihat dari setiap penyelenggaraan Astindo Travel Fair, animo masyarakat pun semakin tinggi. Tingginya animo masyarakat terhadap traveling sejalan dengan meningkatnya kesejahteraan penduduk Indonesia, dan menunjukkan perbaikan perekonomian Indonesia.

Berangkat dari peluang yang ada di pasar, maka PT Hasrat Lestari Gemilang (PT. HLG) yang dimiliki oleh seorang business woman mencoba meraih pangsa pasar bisnis travel agent. PT. HLG yang dibentuk pada tanggal 9 Agustu 2018 memberikan jasa travel dengan tujuan wisata dalam negeri dan telah melakukan ekspansi melayani tujuan wisata ke luar negeri. Berbekal pengalaman ketika beliau masih bekerja pada perusahaan travel agent yang lain, beliau memberanikan diri untuk membuat perusahaan sendiri. Bermula dari hanya membuka penjualan tiket pesawat dengan modal Rp10.000.000,- beliau membuat perencanaan keuangan dengan baik dan tercatat. Dalam dua tahun bisnis travel agent dijalankan, PT. HLG berhasil mendapatkan lebih dari 8 perusahaan yang menjadi konsumen tetap yang menyelenggarakan wisata secara rutin untuk karyawannya. Saat ini perusahaan telah berhasil mengembangkan usahanya dengan omset hampir mencapai 1 milyar dalam 1 tahun.

Produk-produk PT. HLG yang ditawarkan kepada masyarakat adalah sebagai berikut:

1. Pemesanan tiket pesawat

PT. HLG bekerja sama dengan berbagai maskapai domestik maupun internasional yang telah dilakukan secara online, sehingga konsumen tidak perlu datang untuk mengambil tiket.

2. Perjalanan wisata keluarga

PT. HLG memiliki layanan wisata kecil yang terdiri dari anggota keluarga yang dapat dilakukan dengan perjalanan darat maupun pesawat terbang.

3. Perjalanan wisata publik dalam negeri

PT. HLG menawarkan dengan jadwal dan tempat wisata yang telah dirancang dengan beberapa alternatif pilihan di dalam negeri, misalnya wisata merapi di Yogyakarta, wisata budaya di Bali dan lain sebagainya.

4. Perjalanan wisata publik luar negeri

PT. HLG menawarkan dengan jadwal dan tempat wisata yang telah dirancang dengan beberapa alternatif pilihan di luar negeri, misalnya perjalanan mengunjungi negara Asia, Eropa, dan Australia.

5. Perjalanan wisata custom

PT. HLG melayani permintaan wisata dengan tujuan dalam negeri dan luar negeri dari sebuah perusahaan tertentu untuk para karyawannya. Dalam wisata ini, perusahaan bisa melakukan special request untuk tujuan dan jadwal pelaksanaan sesuai dengan harapan perusahaan.

6. Pelayanan pembuatan dokumen visa

Dalam kaitannya dengan produk wisata ke luar negeri, PT. HLG membantu para peserta dalam hal pengurusan visa.

Dalam Kurun waktu 2 (dua) tahun itu pula, sebanyak 3 kali, PT. HLG mendapatkan permintaan untuk menyelenggarakan perjalanan wisata dan budaya ke luar negeri, yaitu 
1. Wisata budaya Spanyol

Tujuan wisata adalah kota Madrid dan Sevilla, yang memiliki ragam budaya unik dan sejarah perpaduan Gipsi, Islam Persia, dan Eropa.

2. Wisata budaya Italia

PT. HLG juga dipercaya untuk memberi layanan Academic Exposure ke kota Milan dan Roma, Italia untuk para CEO dan Direksi perbankan yang melakukan company visit dan study mengenai perkembangan keuangan dan perbankan di belahan dunia Eropa bekerjasama dengan salah satu perguruan tinggi negeri di Jakarta.

3. Wisata akademik dan budaya

Untuk ketiga kalinya PT. HLG mengawal group para CEO untuk melakukan studi mengenai keuangan dan perbankan di St Petersburg dan Moscow, Rusia.

Saat ini PT. HLG telah memasuki tahun ketiga dalam berkiprah di bisnis pelayanan travel agent di Indonesia dan ikut menyumbang peningkatan perekonomian Indonesia melalui pariwisata. PT. HLG memiliki target ekspansi pasar yaitu membuat paket-paket perjalanan wisata publik ke luar negeri dengan menyajikan beberapa alternatif tujuan. PT. HLG memiliki target memberangkatkan wisatawan sebanyak minimal tiga kali dalam satu tahun. PT. HLG juga memiliki target untuk membangun lebih banyak networking dengan mitra travel agent di luar negeri sehingga paket yang ditawarkan memiliki daya tarik dan kemasan yang lebih menarik dengan menerima masukan dari travel agent mitra di negara luar.

PT. HLG menyadari bahwa perusahaan travel agent telah menjamur dan merupakan tantangan bagi perkembangan bisnisnya. PT. HLG harus membuat perencanaan bisnis dengan model yang baik dan tepat untuk menciptakan keunggulan kompetitif dan sustainable. Jumlah penduduk di Indonesia dan perkembangan ekonomi yang pesat merupakan peluang bagi PT. HLG. Kemampuan menganalisis kekuatan dan kelemahan internal untuk menghadapi ancaman dan mengambil kesempatan yang ada, sangat penting dilakukan agar target yang ditetapkan dapat tercapai serta memenangkan pasar.

\section{Visi Misi Perusahaan}

PT. HLG telah memiliki visi dan misi perusahaan agar seluruh resource yang ada di dalam perusahaan dapat mengembangkan inisiatif dan kreatifitas sesuai dengan arah pengembangan perusahaan (company profile PT. HLG, 2018):

Visi: Menjadi biro perjalanan wisata terbaik di Jakarta dengan pelayanan prima pada tahun 2025.

Misi:

1. Membangun personal bounding dengan konsumen dan calon konsumen.

2. Melakukan continues improvement dalam memberikan pelayanan secara tulus.

3. Mengedepankan pelayanan online dengan sistem yang dapat memudahkan akses serta informasi layanan bagi konsumen dan calon konsumen.

\section{Struktur Organisasi}

Tabel 1. Struktur Organisasi PT. HLG 


\begin{tabular}{l|l}
\hline Jabatan & Jumlah \\
\hline Komisaris & 1 orang \\
Direktur & 1 orang \\
Keuangan & 1 orang \\
Marketing & 1 orang \\
Freelance & 1 orang
\end{tabular}

\section{KAJIAN PUSTAKA}

Seorang manajer atau pimpinan sebuah perusahaan harus mengetahui proses bisnis di dalam perusahaannya dan mengetahui tugas yang harus dilakukan agar dapat mengembangkan perusahaan ke arah yang tepat. Pimpinan perusahaan harus mampu mengarahkan resource yang ada untuk bersama-sama mewujudkan visi dan misi perusahaan yang dituangkan dalam standard operating procedure dan job description setiap resource. Para pemimpin dan manajer juga harus dapat menganalisis kekuatan dan kelemahan internal perusahaan untuk meraih peluang dan menghadapi tantangan dari lingkungan eksternal. Keberhasilan sebuah perusahaan tergantung kepada kemampuan manajer atau pimpinan melihat keempat elemen di atas yaitu strengths, weaknesses, opportunities, dan threatss dan merumuskan strategi yang tepat berdasarkan analisis yang dilakukan terhadap ke empat elemen di atas.

Strategi adalah arah dan lingkup organisasi dalam jangka panjang untuk mencapai keuntungan organisasi melalui konfigurasi semua sumber daya yang dimiliki untuk dapat mengatasi tantangan lingkungan sekaligus memenuhi kebutuhan lingkungan bisnis dan harapan pihak-pihak yang berkepentingan (Johnson et al., 2002). Strategi adalah sebagai bentuk perencanaan menyeluruh yang menyatakan bagaimana organisasi mewujudkan misi dan obyektifnya. Wheels dan David (2006). Strategi merupakan cara suatu organisasi untuk mencapai tujuan yang juga merupakan kebijakan dalam menentukan arah dan lingkup organisasi. Perumusan strategi merupakan proses penyusunan langkah-langkah ke depan yang dimaksudkan untuk membangun visi dan misi organisasi, menetapkan tujuan strategis dan merancang strategi untuk mencapai tujuan tersebut dalam rangka menyediakan customer value terbaik.

Beberapa langkah yang perlu dilakukan dalam merumuskan strategi yaitu (Hariadi, 2005):

1. Mengidentifikasi lingkungan yang akan dimasuki oleh perusahaan di masa depan dan menetukan misi perusahaan untuk mencapai visi yang dicita-citakan dalam lingkungan tersebut.

2. Melakukan analisis lingkungan internal dan eksternal dalam rangka mengukur kekuatan dan kelemahan serta peluang dan ancaman yang akan dihadapi perusahaan dalam menjalankan misinya.

3. Merumuskan faktor-faktor ukuran keberhasilan dari strategi-strategi yang dirancang pada analisis sebelumnya.

4. Menentukan tujuan dan target terukur, mengevaluasi berbagai alternatif strategi dengan mempertimbangkan sumber daya yang ada dan kondisi eksternal yang dihadapi.

5. Memilih strategi yang paling sesuai untuk mencapai tujuan jangka pendek dan jangka panjang. 
Berdasarkan pandangan Dan Schendel dan Charles Hofer, Higgins (1985) menjelaskan adanya empat tingkatan dari strategi. Semuanya disebut dengan master strategy, yang terdiri dari enterprise strategy, corporate strategy, business strategy, dan functional strategy.

\section{Enterprise Strategy}

Strategi ini berkaitan dengan respon masyarakat. Masyarakat yang dimaksud adalah kelompok yang berada di luar organisasi yang tidak dapat dikontrol. Dalam masyarakat yang tidak terkendali itu, ada pemerintah dan berbagai kelompok lain seperti kelompok penekan, kelompok politik, dan kelompok sosial lainnya. Jadi dalam strategi enterprise terlihat relasi antara organisasi dan masyarakat luar, sejauh interaksi itu akan dilakukan sehingga dapat menguntungkan organisasi. Strategi itu juga menampakkan bahwa organisasi enar-benar bekerja dan berusaha untuk memberikan pelayanan yang terbaik terhadap tuntutan-tuntutan dan kebutuhan masyarakat.

2. Corporate Strategy

Strategi ini berkaitan dengan misi organisasi, sehingga sering disebut dengan grand strategy yang meliputi bidang yang digeluti oleh suatu organisasi. Pertanyaanapa yang menjadi bisnis atau urusan kita dan bagaimana kita mengendalikan bisnis itu, tidak semata-mata dijawab oleh organisasi bisnis, tetapi juga organisasi pemerintahan dan organisasi nonprofit.

3. Business Strategy

Strategi pada tingkat ini menjelaskan bagaimana merebut pasaran di tengah masyarakat. Bagaimana menempatkan organisasi di hati para penguasa, para pengusaha, dan para pemilik modal. Semua itu dimaksudkan untuk memperoleh keuntungan-keuntungan stratejik yang sekaligus mampu menunjang perkembangan organisasi ke tingkat yang lebih baik.

4. Functional Strategy

Strategi ini merupakan strategi pendukung yang berfungsi untuk menunjang suksesnya strategi lainnya. Ada tiga jenis strategi fungsional, yaitu:

a. Strategi fungsional ekonomi, yaitu mencakup fungsi-fungsi yang memungkinkan organisasi hidup sebagai satu kesatuan ekonomi yang sehat, antara lain yang berkaitan dengan keuangan, pemasaran, penelitian, pengembangan, dan sumber daya.

b. Strategi fungsional manajemen, yaitu mencakup fungsi-fungsi manajemen, antara lain planning, organizing, implementating, controlling, leading, motivating, staffing, communicating, representing, decision making, dan integrating.

c. Strategi isu stratejik, fungsi utamanya adalah mengontrol lingkungan, baik situasi lingkungan yang sudah diketahui maupun yang belum diketahui dan selalu berubah.

\section{SWOT Analisys}

Kotler \& Armstrong (2008:64) analisis SWOT adalah penilaian menyeluruh terhadap kekuatan (strengthss), kelemahan (weaknesseses), peluang (opportunities), dan ancaman (threats) suatu perusahaan. Analisis ini diperlukan untuk menentukan beberapa strategi yang ada di perusahaan. Salah satunya yang kita bahas adalah strategi promosi dan penempatan produk. Jogiyanto (2005:46) SWOT digunakan untuk menilai kekuatan-kekuatan dan 
kelemahan-kelemahan dari sumber-sumber daya yang dimiliki perusahaan dan kesempatankesempatan eksternal dan tantangan-tantangan yang dihadapi. David (Fred R. David, 2008:8) Semua organisasi memiliki kekuatan dan kelemahan dalam area fungsional bisnis. Tidak ada perusahaan yang sama kuatnya atau lemahnya dalam semua area bisnis.

Berikut ini merupakan penjelasan dari SWOT (David,Fred R.,2005:47) yaitu:

1. Kekuatan (Strenghts)

Kekuatan adalah sumber daya, keterampilan, atau keungulan-keungulan lain yang berhubungan dengan para pesaing perusahaan dan kebutuhan pasar yang dapat dilayani oleh perusahaan yang diharapkan dapat dilayani. Kekuatan adalah kompetisi khusus yang memberikan keunggulan kompetitif bagi perusahaan di pasar. Kekuatan atau strengths sumber daya adalah merupakan lingkungan internal perusahaan yang sangat penting untuk diidentifikasi agar perusahaan dapat menggunakan kekuatan tersebut dalam meraih pasar dan menciptakan keunggulan kompetitif.

2. Kelemahan (Weaknesses)

Kelemahan adalah keterbatasan atau kekurangan dalam sumber daya, keterampilan, dan kapabilitas yang secara efektif menghambat kinerja perusahaan. Keterbatasan tersebut dapat berupa fasilitas, sumber daya keuangan, kemampuan manajemen, dan keterampilan pemasaran dapat merupakan sumber dari kelemahan perusahaan. Kelemahan internal perusahaan sangat penting untuk diidentifikasi agar dapat dilakukan evaluasi dan menjadi pedoman bagi perusahaan untuk membuat strategi yang tepat.

3. Peluang (Opportunities)

Peluang adalah situasi penting yang mengguntungkan dalam lingkungan eksternal perusahaan. Trend pergerakan pasar merupakan salah satu sumber peluang, seperti perubahaan teknologi, dan meningkatnya hubungan antara perusahaan dengan pembeli atau pemasok merupakan gambaran peluang bagi perusahaan. Perubahan situasi perekonomian di sebuah negara juga merupakan peluang untuk memasarkan produk sesuai dengan kebutuhan konsumen yang maklin meningkat

4. Ancaman (Threatss)

Ancaman adalah situasi penting yang tidak menguntungan dalam lingkungan perusahaan. Ancaman merupakan pengganggu utama bagi posisi sekarang atau yang diinginkan perusahaan. Adanya peraturan-peraturan pemerintah yang baru atau yang direvisi dapat merupakan ancaman bagi kesuksesan perusahaan. Begitu pula dengan persaingan bisnis dengan competitor yang bergerak pada bisnis yang sama. 


\section{Technological SWOT Analysis Diagram}

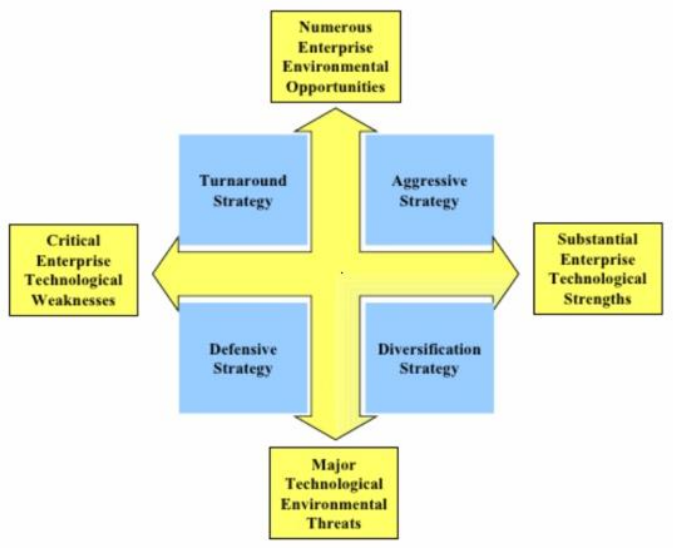

\section{Gambar 1 Diagram SWOT Analysis}

Kuadran 1: SO Strategi, Adalah kondisi yang ideal, perusahaan dapat menggunakan kekuatan perusahaan untuk mengambil setiap kesempatan yang ada

Kuadran 2: WO Strategi, Mengambil kesempatan dengan memfokuskan kegiatan untuk menghindari kelemahan

Kuadran 3: WT Strategi, Meminimalkan kelemahan untuk menghindari ancaman Kuadran 4: ST Strategi, Menggunakan kekuatan perusahaan untuk menghadapi ancaman

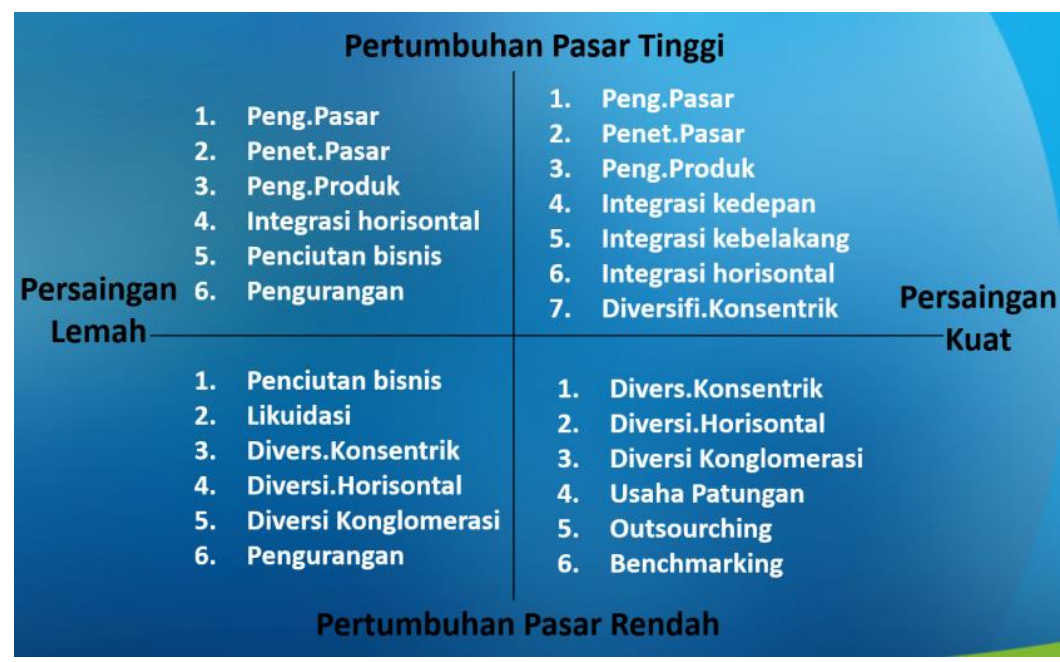

\section{Gambar 2 General Strategy}

\section{Analisis Lingkungan Internal (Strengths and Weaknesses)}

Untuk melakukan evaluasi kekuatan dan kelemahan lingkungan internal perusahaan, pendekatan yang sering digunakan adalah melalui pendekatan Resources-Based View (RBV) yang dikemukakan oleh Barney (2007: 127-162).

Konsep Resource-Based View adalah melakukan inventarisasi sumber daya yang dimiliki oleh perusahaan yaitu:

- Valuable (bernilai tinggi)

- Rare (langka)

- Costly to imitate (sangat mahal untuk ditiru)

- Exploited by organization (dapat diekploitasi) 
Setiap perusahaan memiliki kelemahan dan kekuatan yang berbeda sehingga kinerja perusahaan satu dengan perusahaan yang lain juga berbeda. Begitu pula strategi yang akan digunakan juga berbeda sesuai dengan hasil dari analisis lingkungan internalnya. Dengan konsep RBV ini menunjukkan bahwa competitive advantage dari perusahaan berasal dari lingkungan internal perusahaan. Sumber daya internal organisasi meliputi sumber daya manusia, aset yang dimiliki, kekuatan modal usaha, teknologi yang mendukung, budaya perusahaan, sistem dan prosedur, dan lainnya di dalam perusahaan.

Ragam internal resources ini dapat dikategorikan menjadi tiga bagian besar yaitu:

1. Sumber daya manusia

2. Sumber daya fisik

3. Sumber daya modal kerja perusahaan

\section{Analisis Lingkungan Eksternal}

Proses Yang Dilakukan Dalam Melakukan Analisis Lingkungan Eksternal

\section{Scanning}

Scanning merupakan studi terhadap semua segmen dalam lingkungan eksternal. Perusahaan mengidentifikasi tanda-tanda awal dari perubahan potensi dalam lingkungan eksternal dan mendeteksi perubahan-perubahan yang sedang terjadi. Ketika melakukan scanning, seringkali perusahaan menghadapi data dan informasi yang ambigu, tidak lengkap, dan tidak berkaitan. Scanning lingkungan eksternal merupakan hal penting dan menentukan bagi perusahaan yang bersaing dalam lingkungan yang tidak stabil. Selain itu, aktivitas scanning selaras dengan konteks organisasi. Suatu sistem scanning dirancang untuk lingkungan yang tidak stabil atau cepat berubah.

\section{Monitoring}

Yaitu mengamati perubahan-perubahan lingkungan untuk melihat apakah suatu trend yang penting sudah berkembang di antara hal-hal yang diamati dalam proses scanning. Monitoring yang berhasil adalah apabila mampu mendeteksi makna dalam peristiwaperistiwa lingkungan yang berbeda.

\section{Forecasting}

Scanning dan monitoring berkaitan dengan peristiwa-peristiwa dalam lingkungan eksternal pada suatu waktu. Forecasting adalah meramalkan proyek atau program apa yang harus dijalankan untuk mengantisipasi apa yang mungkin terjadi di masa datang. Proses forecasting ditentukan oleh seberapa cepat proses scanning dan monitoring dapat dijalankan.

\section{Assessing}

Tujuan assesing adalah untuk menentukan waktu dan pengaruh yang signifikan yang diakibatkan dari perubahan-perubahan dan trend-trend lingkungan terhadap strategi perusahaan. Melalui scanning, monitoring, dan forecasting serorang analis dapat memahami lingkungan eksternal. Tujuan assesing adalah untuk memberikan pemahaman atas data yang dihasilkan dari proses sebelumnya kepada organisasi. 


\section{METODE PENELITIAN}

Dalam karya tulis ini, Penulis mencoba menganalisis model bisnis serta strategi bisnis melalui analisis SWOT menggunakan metode descriptive quantitative pendekatan ResourceBased View serta Matrix IE analisis lingkungan eksternal sesuai dengan teori-teori yang dapat diaplikasikan oleh PT. HLG dalam menjalankan proses bisnisnya. Penulis melakukan wawancara dengan pimpinan PT. HLG serta staf yang lain. Penulis menggunakan pendekatan Resource-Based View untuk analisis lingkungan internal dan pendekatan scanning, monitoring, forecasting dan assessing yang dilakukan PT. HLG untuk menganalisis lingkungan eksternal. Dari hasil wawancara maka akan diperoleh posisi PT. HLG di dalam diagram SWOT, dan akan terlihat strategi apa yang tepat digunakan dengan internal resource yang ada.

\section{HASIL DAN PEMBAHASAN Analisis Internal PT. HLG}

Penilaian bobot questionnaire melalui wawancara dengan 5 tenaga kerja di PT. HLG. Nilai 1-5 dengan nilai 1 terkecil dan 5 terbesar.

Tabel 2. Analisis Internal PT. HLG

\begin{tabular}{|c|c|c|c|c|c|c|}
\hline No & RBV & Valuable & Rare & $\begin{array}{l}\text { Costly to } \\
\text { imitate }\end{array}$ & $\begin{array}{l}\text { Exploited by } \\
\text { organization }\end{array}$ & Score \\
\hline \multicolumn{7}{|c|}{ Sumber daya manusia } \\
\hline 1 & $\begin{array}{l}\text { Karyawan yang dimiliki qualified } \\
\text { dan kemampuan berbahasa Inggris }\end{array}$ & 5 & 3 & 3 & 4 & 3.75 \\
\hline 2 & $\begin{array}{l}\text { Karyawan berpengalaman di } \\
\text { bidangnya }\end{array}$ & 5 & 3 & 3 & 3 & 3.50 \\
\hline 3 & $\begin{array}{l}\text { Jumlah karyawan adalah } 5 \text { orang } \\
\text { dengan jobdes yang cukup banyak }\end{array}$ & 2 & 2 & 2 & 2 & 2.00 \\
\hline 4 & $\begin{array}{l}\text { Memiliki hubungan yang baik } \\
\text { dengan konsumen }\end{array}$ & 4 & 4 & 3 & 4 & 3.75 \\
\hline 5 & Tenaga pemasar produk & 2 & 2 & 2 & 2 & $\begin{array}{l}2.00 \\
\mathbf{3 . 0 0}\end{array}$ \\
\hline \multicolumn{7}{|c|}{ Sumber daya fisik } \\
\hline 1 & Variasi produk jasa yang dimiliki & 4 & 1 & 2 & 4 & 2.75 \\
\hline 2 & $\begin{array}{l}\text { Akta pendirian perusahaan dari } \\
\text { Dinas Pariwisata }\end{array}$ & 5 & 5 & 5 & 5 & 5.00 \\
\hline 3 & $\begin{array}{l}\text { Tergabung dalam asosiasi travel } \\
\text { agent di Indonesia }\end{array}$ & 0 & 0 & 0 & 0 & 0 \\
\hline 4 & $\begin{array}{l}\text { Memiliki mitra yang kredibel di luar } \\
\text { negeri }\end{array}$ & 3 & 3 & 2 & 3 & 2.75 \\
\hline 5 & $\begin{array}{l}\text { Fasilitas pendukung yang ada di } \\
\text { perusahaan }\end{array}$ & 2 & 2 & 2 & 2 & 2.00 \\
\hline 6 & $\begin{array}{l}\text { Informasi melalui media sosial dan } \\
\text { website }\end{array}$ & 3 & 1 & 1 & 3 & 2.00 \\
\hline & & & & & & 2.42 \\
\hline \multicolumn{7}{|c|}{ Sumber daya modal kerja perusahaan } \\
\hline 1 & Modal usaha & 2 & 2 & 2 & 2 & 2.00 \\
\hline 2 & Dana promosi & 2 & 2 & 2 & 2 & 2.00 \\
\hline \multirow{2}{*}{\multicolumn{6}{|c|}{ Total score }} & 2.00 \\
\hline & & & & & & 2.47 \\
\hline
\end{tabular}

Dari analisis lingkungan internal di atas, dapat dilihat bahwa total score PT. HLG adalah 2.47, dimana score ini adalah kurang dari setengah score maksimal. Hal ini menunjukkan bahwa internal resources yang dimiliki oleh PT. HLG berada pada posisi lemah (weak). 


\section{Analisis Lingkungan Eksternal}

Penilaian ini adalah hasil dari wawancara dengan karyawan yang bekerja pada PT. HLG. Score yang dihasilkan menunjukkan semakin tinggi, maka semakin tinggi peluang yang ada. Score terdiri dari 1-5, dengan 1 adalah skor terkecil, dan 5 adalah skor tertinggi

Tabel 3. Analisis Eksternal PT. HLG

\begin{tabular}{|c|c|c|}
\hline No & Lingkungan eksternal & Score \\
\hline 1 & Meningkatnya minat masyarakat untuk berwisata & 5 \\
\hline 2 & Meningkatnya perekonomian Indonesia & 5 \\
\hline 3 & $\begin{array}{l}\text { Kebijakan pemerintah untuk meningkatkan penghasilan negara dari } \\
\text { sektor pariwisata }\end{array}$ & 4 \\
\hline 4 & Dukungan pemerintah terhadap usaha start up & 4 \\
\hline 5 & Semakin banyak jumlah perusahaan travel agent & 2 \\
\hline 6 & Nilai tukar rupiah terhadap dolar yang sedang melemah & 2 \\
\hline 7 & Jumlah maskapai penerbangan yang meningkat & 3 \\
\hline & Total score dibagi dengan 7 & 3.50 \\
\hline
\end{tabular}

Dari table analisis lingkungan eksternal, dapat dilihat bahwa score yang didapat adalah 3.5 dari skor maksimal adalah 5, sehingga dapat disimpulkan bahwa peluang yang ada di lingkungan eksternal cukup tinggi.

Berdasarkan wawancara yang dilakukan, pimpinan PT. HLG sebenarnya telah melakukan proses analisis lingkungan eksternal sebagai berikut:

1. Scanning

Pimpinan PT. HLG menyebutkan bahwa kondisi politik dan ekonomi Indonesia yang dirasakan adalah fluktuatif begitu pula dengan nilai tukar rupiah terhadap mata uang negara lain. Kemajuan teknologi juga dengan cepat mengubah pola konsumen untuk membeli jasa khususnya jasa yang ditawarkan oleh travel agent. Generasi milenial adalah generasi yang menyukai perubahan dan suasana baru, sehingga lingkungan eksternal saat ini bersifat labil.

2. Monitoring

Pimpinan PT. HLG telah melakukan beberapa identifikasi setiap terdapat perubahan tren yang diperoleh dari hasil scanning. Dari hasil scanning, pimpinan PT. HLG menemukan bahwa saat ini konsumen lebih senang mempurchase barang dan jasa melalui internet, tanpa harus bertemu muka dengan penjual barang atau jasa. Tren ini mengaharuskan PT. HLG untuk mulai menggunakan media social sebagai sarana informasi dan penjualan.

3. Forecasting

Dari hasil wawancara dengan pimpinan PT. HLG, forecasting atau prediksi jangka panjang mengenai bisnis travel agent juga sudah diperoleh, bahwa PT. HLG memprediksi tendensi masyarakat Indonesia akan melakukan wisata dan study budaya ke negara Eropa. 


\section{Tabel 4. Matriks SWOT}

\begin{tabular}{|c|c|c|}
\hline SWOT MATRIX & $\begin{array}{l}\text { Kekuatan (Strengths) } \\
\text { 1. Karyawan yang dimiliki qualified } \\
\text { dan kemampuan berbahasa Inggris } \\
\text { 2. Karyawan berpengalaman di } \\
\text { bidangnya } \\
\text { 3. Memiliki hubungan yang baik } \\
\text { dengan konsumen } \\
\text { 4. Variasi produk jasa yang dimiliki } \\
\text { 5. Akta pendirian perusahaan dari } \\
\text { Dinas Pariwisata } \\
\text { 6. Memiliki mitra yang kredible di } \\
\text { luar negeri }\end{array}$ & $\begin{array}{l}\text { Kelemahan (Weaknesses) } \\
\text { 1. Jumlah karyawan adalah } 5 \\
\text { orang dengan jobdes yang } \\
\text { cukup banyak } \\
\text { 2. Tenaga pemasar produk } \\
\text { 3. Fasilitas pendukung yang ada } \\
\text { di perusahaan } \\
\text { 4. Informasi melalui media social } \\
\text { dan website } \\
\text { 5. Modal usaha } \\
\text { 6. Dana promosi }\end{array}$ \\
\hline $\begin{array}{l}\text { Peluang (Opportunities) } \\
\text { 1. Meningkatnya minat masyarakat } \\
\text { untuk berwisata } \\
\text { 2. Meningkatnya perekonomian } \\
\text { Indonesia } \\
\text { 3. Kebijakan pemerintah untuk } \\
\text { meningkatkan penghasilan } \\
\text { negara dari sektor pariwisata } \\
\text { 4. Dukungan pemerintah terhadap } \\
\text { usaha start up } \\
\text { 5. Jumlah maskapai penerbangan } \\
\text { yang meningkat }\end{array}$ & $\begin{array}{l}\text { Melakukan strategi pengembangan } \\
\text { pasar: } \\
\text { Mengambil peluang dengan } \\
\text { menonjolkan personal approach dan } \\
\text { personal bounding dengan } \\
\text { konsumen. } \\
\text { Menguatkan mitra luar negeri dan } \\
\text { membuat paket wisata yang lebih } \\
\text { bermakna budaya dan edukasi. }\end{array}$ & $\begin{array}{l}\text { Melakukan strategi } \\
\text { pengembangan pasar, strategi } \\
\text { pengembangan produk, dan } \\
\text { strategi penetrasi pasar } \\
\text { Meningkatkan pangsa pasar } \\
\text { dengan menjalin kerja sama } \\
\text { dengan marketing lepas, } \\
\text { mempertahankan konsumen lama, } \\
\text { mencari konsumen baru, dan } \\
\text { meningkatkan promosi melalui } \\
\text { media sosial }\end{array}$ \\
\hline $\begin{array}{l}\text { Ancaman (Threatsh) } \\
\text { 1. Semakin banyak jumlah } \\
\text { perusahaan travel agent } \\
\text { 2. Nilai tukar rupiah terhadap } \\
\text { dolar yang sedang melemah }\end{array}$ & $\begin{array}{l}\text { Melakukan strategi penetrasi pasar } \\
\text { dan pengembangan produk } \\
\text { Menggunakan keunggulan kualitas } \\
\text { karyawan untuk mengembangkan } \\
\text { produk yang superior yaitu } \\
\text { menguatkan networking dengan mitra } \\
\text { di luar negeri dan menciptakan variasi } \\
\text { wisata ke luar negeri. }\end{array}$ & $\begin{array}{l}\text { Melakukan strategi integrasi } \\
\text { horizontal }\end{array}$ \\
\hline
\end{tabular}

Dari matriks SWOT di atas, dapat disimpulkan bahwa terdapat 4 (empat) strategi bisnis yang dapat diterapkan oleh PT. Hasrat Lestari Gemilang, yaitu penetrasi pasar, pengembangan produk, pengembangan pasar, dan integrasi horisontal.

\section{MATRIX IE (INTERNAL EXTERNAL)}

Disamping analisis SWOT berikut analisis menggunakan Matrix Internal External untuk membandingkan hasil dari analisis SWOT dengan hasil dari analisis menggunakan Matrix IE.

Di dalam diagram IE terdapat 9 sel strategi perusahaan, yang dikelompokkan menjadi 3 strategi utama, yaitu:

- Growth strategy adalah strategi pertumbuhan (sel 1,2,5) upaya diversifikasi (sel 7 dan 8).

- Stability strategy diterapkan tanpa mengubah arah strategi yang telah ditetapkan.

- Retrenchment strategy adalah strategi untuk memperkecil atau mengurangi usaha yang dilakukan perusahaan (sel 3, 6, dan 9). 


\section{Tabel 5. Matrix IFE}

Key Internal Factor

\begin{tabular}{lllll}
\hline Strengths & Bobot & Skor & $\begin{array}{l}\text { Konversi } \\
\text { skala 4 }\end{array}$ & Total \\
\hline $\begin{array}{l}\text { 1. Karyawan yang dimiliki qualified dan kemampuan berbahasa } \\
\text { Inggris }\end{array}$ & 0.17 & 3.75 & 3 & 0.51 \\
\hline $\begin{array}{l}\text { 2. Karyawan berpengalaman di bidangnya } \\
\text { 3. Memiliki hubungan yang baik dengan konsumen }\end{array}$ & 0.12 & 3.5 & 2.8 & 0.336 \\
\hline 4. Variasi produk jasa yang dimiliki & 0.1 & 3.75 & 3 & 0.3 \\
\hline 5. Akta pendirian perusahaan dari Dinas Pariwisata & 0.07 & 2.75 & 2.2 & 0.154 \\
\hline 6. Memiliki mitra yang kredible di luar negeri & 0.05 & 5 & 4 & 0.2 \\
\hline & 0.04 & 2.75 & 2.2 & 0.088 \\
\hline $\begin{array}{l}\text { Weaknesses } \\
\text { 1. Jumlah karyawan adalah 5 orang dengan jobdes yang cukup } \\
\text { banyak }\end{array}$ & Bobot & Skor & $\begin{array}{l}\text { Konversi } \\
\text { skala 4 }\end{array}$ & Total \\
\hline 2. Tenaga pemasar produk & 0.1 & 2 & 1.6 & 0.16 \\
\hline 3. Fasilitas pendukung yang ada di perusahaan & 0.07 & 2 & 1.6 & 0.112 \\
\hline 4. Informasi melalui media social dan website & 0.05 & 2 & 1.6 & 0.08 \\
\hline 5. Modal usaha & 0.09 & 2 & 1.6 & 0.144 \\
\hline 6. Dana promosi & 0.04 & 2 & 1.6 & 0.064 \\
\hline & 0.1 & 2 & 1.6 & 0.16 \\
\hline
\end{tabular}

Tabel 6. Matrix EFE

Key External Factor

\begin{tabular}{lllll}
\hline Opportunities & Bobot & Skor & $\begin{array}{l}\text { Konversi } \\
\text { skala 4 }\end{array}$ & Total \\
\hline $\begin{array}{l}\text { 1. Meningkatnya minat masyarakat untuk berwisata } \\
\text { 2. Meningkatnya perekonomian Indonesia }\end{array}$ & 0.17 & 5 & 4 & 0.68 \\
\hline $\begin{array}{l}\text { 3. Kebijakan pemerintah untuk meningkatkan } \\
\text { penghasilan negara dari sektor pariwisata }\end{array}$ & 0.2 & 5 & 4 & 0.8 \\
\hline $\begin{array}{l}\text { 4. Dukungan pemerintah terhadap usaha start up } \\
\text { 5. Jumlah maskapai penerbangan yang meningkat }\end{array}$ & 0.09 & 4 & 3.2 & 0.576 \\
\hline & & 4 & 3.2 & 0.288 \\
\hline \multicolumn{1}{c}{ Threats } & Bobot & Skor & $\begin{array}{l}\text { Konversi } \\
\text { skala 4 }\end{array}$ & Total \\
\hline $\begin{array}{l}\text { 1. Semakin banyak jumlah perusahaan travel agent } \\
\text { 2. Nilai tukar rupiah terhadap dolar yang sedang } \\
\text { melemah }\end{array}$ & 0.19 & 2 & 1.6 & 0.216 \\
\hline & 0.08 & 2 & 1.6 & 0.128 \\
\hline
\end{tabular}

Dari matrix IFE dan EFE menunjukkan bahwa rata-rata skor adalah 2.65, secara internal PT. HLG berada di posisi lemah yaitu 2.308 di bawah rata-rata, dan factor eksternal berada di angka 2.992 melebihi rata-rata. Hal ini menunjukkan bahwa PT Hasral Lestari Gemilang berada di sel V yaitu Growth Strategy. 


\section{Tabel 7. IE Matrix}

\begin{tabular}{|l|r|}
\hline EFE & $\mathbf{2 . 9 9 2}$ \\
\hline IFE & $\mathbf{2 . 3 0 8}$ \\
\hline
\end{tabular}

The IFE total weighted score

\begin{tabular}{|c|c|c|c|c|}
\hline & & Strong(3.0-4.0) & Everage(2.0-2.99) & Weak(1.0-1.99) \\
\hline & $\begin{array}{l}\operatorname{High}(3.0- \\
4.0)\end{array}$ & I & II & III \\
\hline $\begin{array}{l}\text { The EFE total } \\
\text { weighted score }\end{array}$ & $\begin{array}{l}\text { Medium(2.0- } \\
2.99)\end{array}$ & IV & $\begin{array}{c}\text { PT. HLG } \\
(2.308 ; 2.992)\end{array}$ & VI \\
\hline & $\begin{array}{l}\text { Low(1.0- } \\
1.99)\end{array}$ & VII & VIII & IX \\
\hline
\end{tabular}

\section{KESIMPULAN DAN SARAN}

Melihat hasil analisis lingkungan internal dan eksternal PT. HLG melalui analisis Strengths, Weaknesses, Opportunities, dan Threats, ditemukan bahwa kekuatan PT. HLG adalah pada sumber daya manusia yang quailified, dengan kemampuan interpersonal yang baik, pengalaman, dan kemampuan berbahasa Inggris. PT. HLG memiliki peluang yang besar untuk dapat mencapai visi perusahaan yaitu menjadi perusahaan travel agent terbaik di Jakarta pada tahun 2025 dengan dukungan para karyawan yang unggul dan dapat bekerja secara efisien dan efektif. Kelemahan yang tampak selain pada modal kerja yang perlu diperkuat untuk melakukan ekspansi, juga dari jumlah karyawan yang sedikit dan memiliki job description yang cukup luas. Sebagai contoh satu orang tenaga marketing juga memiliki tugas mengawal peserta ketika melakukan wisata di dalam negeri maupun luar negeri. Ketika karyawan tersebut sedang melakukan tugas mengawal group wisatawan, maka tugas marketing diserahkan kepada karyawan lain yang bertugas di bidang yang berbeda, sehingga karyawan yang menggantikan kurang menguasai product knowledge perusahaan.

Total score yang diperoleh dari analisis SWOT adalah 2.47 untuk analisis internal dan 3.5 untuk analisis eksternal. Hal ini menunjukkan bahwa posisi PT. HLG pada matriks SWOT adalah pada kuadran 2 yaitu WO Strategi, dimana peluang pasar besar namun internal perusahaan menunjukkan bahwa perusahaan masih lemah. Perusahaan harus dapat mengambil opportunities yang ada dengan meminimalkan kelemahan internal resources. Strategi yang digunakan berdasarkan analisis SWOT adalah melakukan strategi pengembangan pasar, strategi pengembangan produk, dan strategi penetrasi pasar yaitu dengan meningkatkan pangsa pasar dengan menjalin kerja sama dengan marketing lepas, mempertahankan konsumen lama, mencari konsumen baru, dan meningkatkan promosi melalui media social

Hasil analisis dengan menggunakan Matrix IE menunjukkan hasil yang sama yaitu dengan rata-rata skor adalah 2.65, secara internal PT. HLG berada di posisi lemah yaitu 2.308 di bawah rata-rata, dan faktor eksternal berada di angka 2.992 melebihi rata-rata. Hal ini menunjukkan bahwa PT Hasral Lestari Gemilang berada di sel V yaitu Growth Strategy. 
Peluang untuk mengembangkan usaha masih sangat luas, namun PT. HLG juga menggunakan strategi untuk menghindari ancaman dan melakukan improvement terhadap kelemahan perusahaan.

\section{Saran Perbaikan}

Dari analisis kelemahan internal, optimalisasi kekuatan yang dimiliki, serta melihat peluang dan ancaman dari faktor eksternal, maka penulis dapat memberikan saran perbaikan:

1. Mendaftarkan perusahaan ke dalam asosiasi ASITA dan ASTINDO agar masyarakat lebih mengenal eksistensi PT. HLG dan juga membuka networking dengan perusahaan sejenis.

2. Perlu menambah jumlah karyawan khususnya tenaga marketing untuk mempromosikan produk PT. HLG.

3. Melakukan tahap assessing setelah scanning, monitoring, dan forecasting dilakukan, agar pemahaman mengenai data yang diperoleh dapat diketahui oleh seluruh karyawan yang terlibat dalam proses bisnis.

4. Meningkatkan promosi, informasi, dan penjualan melalui media sosial dan penjualan online.

5. Memperbaiki website PT. HLG agar tampak lebih menarik dan komunikatif.

Meningkatkan networking dengan mitra luar negeri dan menciptakan variasi produk wisata luar negeri dengan menambah muatan edukasi untuk pangsa pasar para eksekutif muda.

\section{DAFTAR RUJUKAN}

Ali, Hapzi. 2020. Modul Strategic Management Program Studi Magister Management. UMB Jakarta.

Barney, Jay B. (2007). Gaining and sustaining competitive advantage, 3rd ed., New Jersey: Pearson Prentice Hall.

Aryadita, 2019. https://www.dictio.id/t/apa-yang-dimaksud-dengan-teori-resource-basedview/120533, (28 Maret 2020 jam 15.25).

Ainan, 2017. http://frequencia89.blogspot.com/2017/04/internal-external-matrix.html, (28 Maret 2020 jam 21.05).

Biro Pusat Statistik. (2020). Jumlah Penduduk Provinsi DKI Jakarta Menurut Kelompok

Umur dan Jenis Kelamin 2018. https://jakarta.bps.go.id/dynamictable/2019/09/16/58, (28 Maret 2020 jam 2130).

Rothaermel, Frank. 2019. Strategic Management, Mc Graw Hill Education.

Anonim, 2020. http://image.slidesharecdn.com/technologicalswotanalysisdiagram-

110308084936-phpapp01/95/technological-swot-analysis-diagram-1728.jpg?cb=1299596855, (28 Maret 2020, jam 16.05).

Purnomo, R. 2013. Resource-Based View dan Keunggulan Bersaing Berkelanjutan: Sebuah Telaah Kritis Terhadap Pemikiran Jay Barney (1991). Sustainable Competitive Advantage (SCA), 2013.

Kuncoro, E. (2010). Analisis Perumusan Strategi Bisnis pada PT. Samudera Nusantara

Logistido. BINUS Business Review, Vol.1 No.1 Mei 2010: 169-184.

Zainal, H., Ali, H. (2019). Analisa SWOT Bisnis Minimarket 212Mart di Taman Meruya Ilir Jakarta Barat. Scholar, researchgate.net. 
Hanafi Fadli, L. (2019). STRATEGIC MANAGEMENT ANALISIS SWOT Pada PT. Gajah Tunggal Tbk. Jurnal Ekonomi Manajemen Sistem Informasi, 1(2), 106-114. https://doi.org/10.31933/jemsi.v1i2.61 